\title{
A comparison of hinge craniotomy and decompressive craniectomy for the treatment of malignant intracranial hypertension: early clinical and radiographic analysis
}

\author{
Tyler J. Kenning, M.D., Ravi H. Gandhi, M.D., and John W. German, M.D. \\ Division of Neurosurgery, Albany Medical Center, Albany, New York
}

\begin{abstract}
Object. Hinge craniotomy (HC) has recently been described as an alternative to decompressive craniectomy (DC). Although HC may obviate the need for cranial reconstruction, an analysis comparing HC to DC has not yet been published.

Methods. A retrospective review was conducted of 50 patients who underwent cranial decompression (20 with HC, 30 with DC). Baseline demographics, neurological examination results, and underlying pathology were reviewed. Clinical outcome was assessed by length of ventilatory support, length of intensive care unit stay, and survival at discharge. Control of intracranial hypertension was assessed by average daily intracranial pressure (ICP) for the duration of ICP monitoring and an ICP therapeutic intensity index. Radiographic outcomes were assessed by comparing preoperative and postoperative CT scans for: 1) Rotterdam score; 2) postoperative volume of cerebral expansion; 3) presence of uncal herniation; 4) intracerebral hemorrhage; and 5) extraaxial hematoma. Postoperative CT scans were analyzed for the size of the craniotomy/craniectomy and magnitude of extracranial herniation.

Results. No significant differences were identified in baseline demographics, neurological examination results, or Rotterdam score between the HC and DC groups. Both HC and DC resulted in adequate control of ICP, as reflected in the average ICP for each group of patients $(\mathrm{HC}=12.0 \pm 5.6 \mathrm{~mm} \mathrm{Hg}, \mathrm{DC}=12.7 \pm 4.4 \mathrm{~mm} \mathrm{Hg} ; \mathrm{p}>0.05)$ at the same average therapeutic intensity index $(\mathrm{HC}=1.2 \pm 0.3, \mathrm{DC}=1.2 \pm 0.4 ; \mathrm{p}>0.05)$. The need for reoperation $(3[15 \%]$ of 20 patients in the HC group, 3 [10\%] of 30 patients in the DC group; $p>0.05)$, hospital survival (15 [75\%] of 20 in the HC group, $21[70 \%]$ of 30 in the DC group; $p>0.05)$, and mean duration of both mechanical ventilation $(9.0 \pm$ 7.2 days in the HC group, $11.7 \pm 12.0$ days in the DC group; $\mathrm{p}>0.05)$ and intensive care unit stay $(11.6 \pm 7.7$ days in the HC group, $15.6 \pm 15.3$ days in the DC group; $p>0.05)$ were similar. The difference in operative time for the two procedures was not statistically significant (130.4 \pm 71.9 minutes in the HC group, $124.9 \pm 63.3$ minutes in the DC group; $p>0.05)$. The size of the cranial defect was comparable between the 2 groups. Postoperative imaging characteristics, including Rotterdam score, also did not differ significantly. Although a smaller volume of cerebral expansion was associated with HC $(77.5 \pm 54.1 \mathrm{ml})$ than DC $(105.1 \pm 65.1 \mathrm{ml})$, this difference was not statistically significant.

Conclusions. Hinge craniotomy appears to be at least as good as DC in providing postoperative ICP control and results in equivalent early clinical outcomes. (DOI: 10.3171/2009.4.FOCUSO960)
\end{abstract}

\section{Key Words • decompressive craniectomy $\quad \bullet \quad$ hinge craniotomy $\bullet$ cerebral decompression • intracranial hypertension}

\footnotetext{
$\mathrm{C}$ RANIAL decompression for the treatment of medically refractory intracranial hypertension was first reported by Kocher in 1901 and Cushing in $1908.4,16$ In the century following its introduction, its role remained controversial. Recently, many have reported a significant reduction in ICP and even a positive effect on outcome using this technique., ${ }^{3,9,20}$ Currently, despite

Abbreviations used in this paper: $\mathrm{BMI}=$ body mass index; $\mathrm{DC}=$ decompressive craniectomy; $\mathrm{EDH}=$ epidural hematoma; GCS = Glasgow Coma Scale; $\mathrm{HC}=$ hinge craniotomy; $\mathrm{ICH}=$ intracerebral hemorrhage; ICP = intracranial pressure; ICU = intensive care unit; INR = international normalized ratio; IVH = intraventricular hemorrhage; $\mathrm{MCA}=$ middle cerebral artery; $\mathrm{PT}=$ prothrombin time; $\mathrm{PTT}=$ partial thromboplastin time; $\mathrm{SDH}=$ subdural hemorrhage; $\mathrm{TII}=$ therapeutic intensity index.
}

the paucity of randomized trials, DC has become an accepted and effective therapy for patients with malignant intracranial hypertension.

Like any other surgical procedure, there is morbidity associated with DC. . $2,8,11,14$ With a large bone defect, there is a potential risk to the exposed underlying brain, which may require the use of protective headgear. Delayed postoperative seizures have been reported in 37\% and hydrocephalus in $40 \%$ of patients after DC..$^{10,14}$ Neurological worsening has also been described after craniectomy with improvement following cranioplasty. ${ }^{19}$ In addition, as many as $17 \%$ of patients will have chronic, debilitating headaches that only improve with replacement of the cranial plate. ${ }^{5}$ Cranioplasty requires a second operation performed under general anesthesia and exposes the pa- 


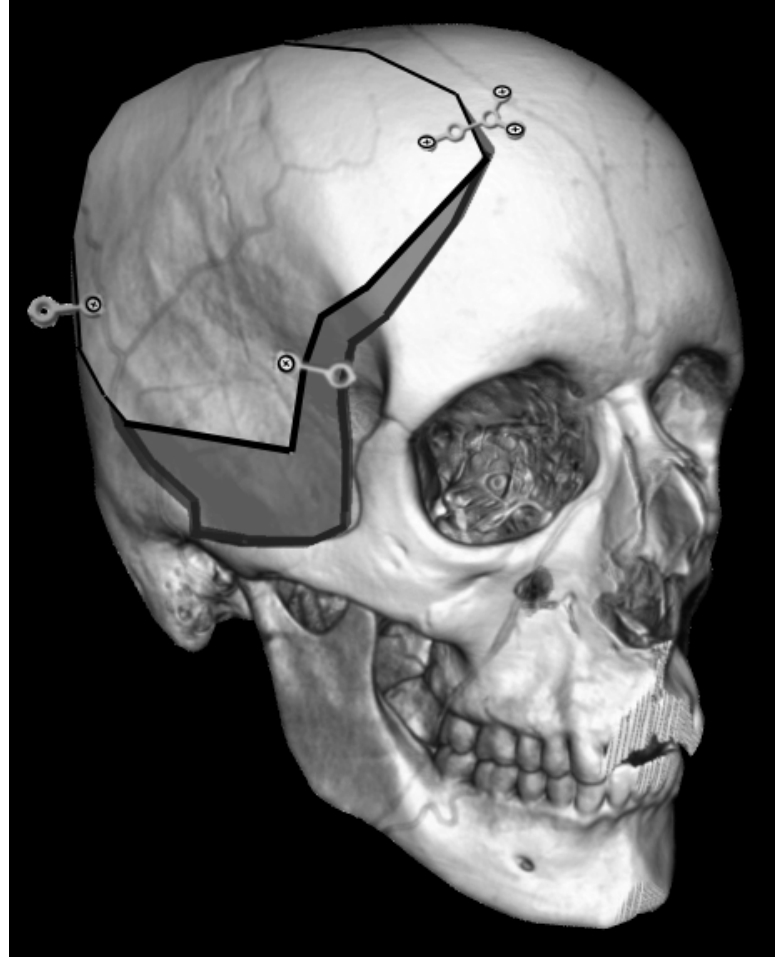

FIG. 1. Illustration of the technique of HC. A single Y-shaped plate secures the bone flap to the surrounding skull, allowing for elevation of the flap with underlying cerebral edema. Peripheral plates prevent bone flap subsidence following resolution of the edema.

tient to additional potential complications. Cranioplasty has a significant infection risk with many patients requiring removal of the autologous cranial plate or prosthetic with subsequent revision.7,10,14,15 In addition, resorption of the bone plate can be a problem, especially in the pediatric population. ${ }^{17,10}$

The ideal procedure for cranial decompression would be one that combines the effectiveness of DC but limits the aforementioned difficulties with which it is associated. In 2007, three investigative groups reported on the use of HC. ${ }^{6,12,17}$ This procedure involves resecuring the cranial plate in a noncircumferential fashion to the underlying skull at the time of the initial decompression, allowing for cerebral expansion through the cranial defect. By allowing the native plate to remain in place, there is a limited cosmetic defect once the cerebral edema resolves and the need for delayed cranioplasty is limited. Despite these potential advantages, the utility of $\mathrm{HC}$ for the relief of elevated ICP is "yet to be determined" and may be only appropriate for "borderline" cases. ${ }^{12}$ To date, there does not exist a published comparison of $\mathrm{DC}$ and $\mathrm{HC}$ in the treatment of malignant intracranial hypertension.

\section{Methods \\ Patient Characteristics \\ We conducted a retrospective chart review of 50 pa- tients undergoing cerebral decompression for treatment}

T.J. Kenning, R.H. Gandhi, and J.W. German

TABLE 1: Intracranial pressure TII*

\begin{tabular}{cl}
\hline Score & \multicolumn{1}{c}{ Therapy } \\
\hline 1 & head elevation and sedation \\
2 & hyperosmotics (such as mannitol and hypertonic saline) \\
3 & acute hyperventilation \\
4 & paralytics \\
5 & barbiturate coma \\
\hline
\end{tabular}

* For each day of ICP monitoring, the maximal therapy administered for ICP control was determined and the patient was assigned one of the corresponding values (1-5) for that day.

of malignant intracranial hypertension related to mass lesions. These patients were all treated at a single institution (Albany Medical Center) by 9 different neurosurgeons over a 25-month period (November 2006 to December 2008).

\section{Surgical Decision-Making}

In the current patient series, the decision to perform either an HC or DC was left to the discretion of the attending neurosurgeon. Since January 2007 the senior author (J.W.G.) has uniformly applied the technique of $\mathrm{HC}$ whenever it was believed that a patient would benefit from cerebral decompression. The sole exception to this policy was a patient who was hypotensive and hypoxic with multiple traumatic injuries, who died within hours after presenting with an acute SDH and massive cerebral swelling; in this patient, it was difficult to close the scalp. As local experience with the technique expanded, other attending neurosurgeons have adopted it. In the current patient series the senior author performed $13(65 \%)$ of the $20 \mathrm{HCs}$. The remaining $7 \mathrm{HCs}(35 \%)$ were performed at the discretion of the individual attending neurosurgeon.

In general, patients with trauma and intracranial hy-

\section{TABLE 2: Rotterdam score calculation*}

\begin{tabular}{|c|c|}
\hline Category & Score \\
\hline \multicolumn{2}{|l|}{ basal cisterns } \\
\hline normal & 0 \\
\hline compressed & 1 \\
\hline absent & 2 \\
\hline \multicolumn{2}{|l|}{ midline shift } \\
\hline$\leq 5 \mathrm{~mm}$ & 0 \\
\hline$>5 \mathrm{~mm}$ & 1 \\
\hline \multicolumn{2}{|l|}{ epidural mass lesion } \\
\hline present & 0 \\
\hline absent & 1 \\
\hline \multicolumn{2}{|c|}{ intraventricular or subarachnoid blood } \\
\hline absent & 0 \\
\hline present & 1 \\
\hline adjustment & +1 \\
\hline
\end{tabular}

* From Maas et al., 2007.

$\uparrow$ Scores based on CT findings. 


\section{Hinge craniotomy versus decompressive craniectomy}

TABLE 3: Summary of patients undergoing HC*

\begin{tabular}{|c|c|c|c|c|c|c|c|}
\hline Cause & $\begin{array}{c}\text { Age } \\
\text { (yrs), } \\
\text { Sex }\end{array}$ & $\begin{array}{l}\text { Motor } \\
\text { GCS } \\
\text { Score }\end{array}$ & Mechanism & CT Finding & $\begin{array}{l}\text { MLS } \\
(\mathrm{mm})\end{array}$ & $\begin{array}{c}\text { Rot- } \\
\text { terdam } \\
\text { Score }\end{array}$ & Survival \\
\hline \multicolumn{8}{|l|}{ trauma } \\
\hline & $26, M$ & 2 & nonpenetrating GSW & SDH, GSW & 8.6 & 4 & yes \\
\hline & $55, \mathrm{~F}$ & 2 & fall & $\mathrm{SDH}$ & 22 & 6 & no \\
\hline & $71, \mathrm{M}$ & 4 & MVA & SDH & 18 & 2 & yes \\
\hline & $51, \mathrm{M}$ & 4 & fall & $\mathrm{SDH}, \mathrm{EDH}, \mathrm{ICH}$ & 14 & 2 & yes \\
\hline & $56, M$ & 3 & high-speed blunt object & SDH, EDH, open fracture & 15 & 4 & yes \\
\hline & $36, M$ & 2 & MVA & $\mathrm{SDH}$ & 3 & 3 & yes \\
\hline & $25, M$ & 6 & MCC & $\mathrm{SDH}$ & 7 & 2 & yes \\
\hline & $60, M$ & 6 & fall & $\mathrm{SDH}, \mathrm{ICH}$ & 7 & 4 & yes \\
\hline & $31, \mathrm{M}$ & 4 & MVA & $\mathrm{SDH}, \mathrm{ICH}$ & 10 & 2 & yes \\
\hline & $39, \mathrm{M}$ & 4 & MCC & $\mathrm{ICH}$ & 14 & 4 & yes \\
\hline & $77, \mathrm{~F}$ & 5 & fall & $\mathrm{SDH}, \mathrm{ICH}$ & 13 & 3 & no \\
\hline & $39, \mathrm{M}$ & 5 & assault & $\mathrm{SDH}, \mathrm{ICH}$ & 8 & 3 & yes \\
\hline \multicolumn{8}{|l|}{ infarct } \\
\hline & $72, \mathrm{M}$ & 2 & rt M1 occlusion & hypodensity of entire MCA distribution & 16 & 2 & no \\
\hline & $44, \mathrm{~F}$ & 6 & rt M1 occlusion & hypodensity >2/3 MCA distribution & 5 & 2 & no \\
\hline & $52, \mathrm{M}$ & 5 & rt ICA occlusion & hypodensity entire MCA distribution & 5 & 3 & yes \\
\hline & $43, \mathrm{~F}$ & 5 & It M1 occlusion & hypodensity >2/3 MCA distribution & 12 & 4 & yes \\
\hline \multicolumn{8}{|l|}{$\mathrm{ICH}$} \\
\hline & $66, M$ & 5 & hemorrhagic conversion of It MCA infarct & $118 \mathrm{ml}$ It parietal ICH & 12.4 & 3 & no \\
\hline & $69, \mathrm{~F}$ & 5 & lobar, suspected amyloid angiopathy & $44 \mathrm{ml} \mathrm{rt} \mathrm{temporal} \mathrm{ICH}$ & 9 & 3 & yes \\
\hline & $45, \mathrm{~F}$ & 2 & hypertensive hemorrhage & $60 \mathrm{ml} \mathrm{rt} \mathrm{basal} \mathrm{ganglia} \mathrm{ICH} \mathrm{w/IVH}$ & 10 & 3 & yes \\
\hline & $53, M$ & 5 & hypertensive hemorrhage & $78 \mathrm{ml}$ It basal ganglia & 11 & 4 & yes \\
\hline
\end{tabular}

* GSW = gunshot wound; ICA = internal carotid artery; MCC = motorcycle collision; MLS = midline shift; MVA = motor vehicle accident.

pertension demonstrating clinical evidence of cerebral herniation with a radiographically confirmed intracranial mass lesion were taken directly to the operating room for decompression. In addition, mass effects with $\geq 5-\mathrm{mm}$ midline shift were treated with immediate surgery. In transport to the operating room, these individuals may have received medical management (such as hyperventilation therapy and osmotic therapy) for intracranial hypertension.

Patients suffering an MCA infarct involving a large percentage of the vascular distribution were treated at variable time points based largely on the clinical judgment of the treating neurosurgeon. These patients received cerebral decompression either "prophylactically," after demonstration of medically refractory intracranial hypertension as recorded by ICP monitoring, or after development of a cerebral herniation syndrome.

\section{Surgical Technique}

Incision and Cranial Exposure. Hinge craniotomies were performed utilizing the technique described by
Schmidt et al., ${ }^{17}$ Ko and Segan, ${ }^{12}$ and Goettler and Tucci. ${ }^{6}$ Briefly, the patient was taken to the operating room where general anesthesia was induced. The patient was placed either supine with the head turned or in the lateral decubitus position to allow the sagittal suture to be as close to parallel as possible with the floor. The head and neck were then elevated above the heart to maximize venous return. The scalp was then shaved, prepared, and draped in the usual fashion. A standard skin incision in the shape of a (reverse) question mark was marked beginning 1 centimeter in front of the tragus, extending above and behind the ear to approximately the posterior mastoid line and then curving forward to within 1 centimeter from the midline to end at or near the hairline. The scalp was incised and reflected forward off the underlying temporalis fascia and muscle. The root of the temporozygomatic process was identified and the temporalis fascia and muscle were then divided using monopolar cautery. The temporalis muscle was mobilized off the underlying skull using a periosteal elevator. The exposed skull was then inspected to ensure that the pterion and the temporal bone had been adequately exposed. 


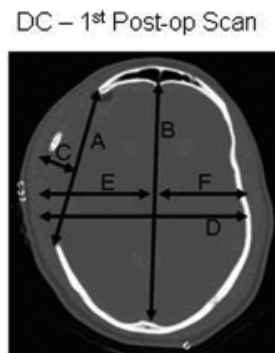

HC - 1st Post-op Scan
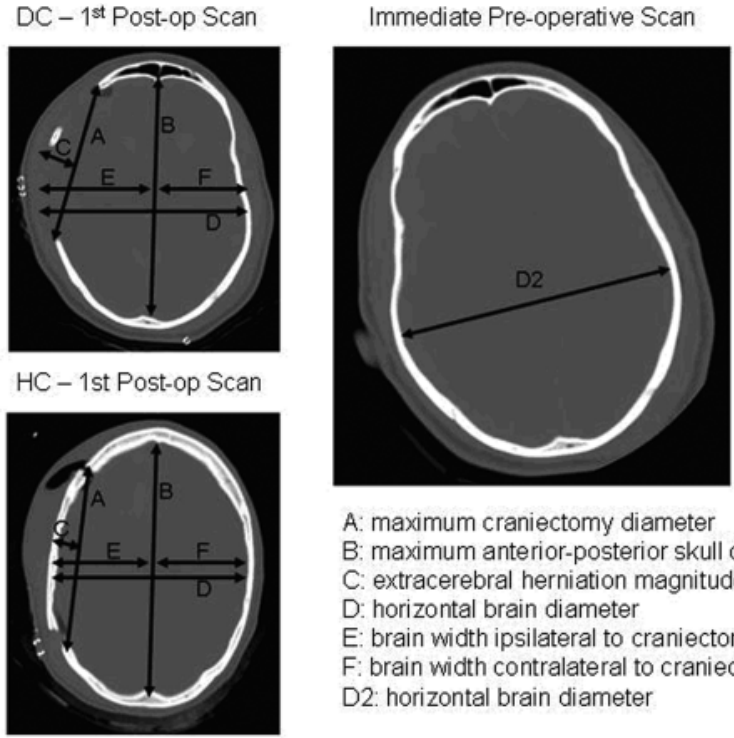

A: maximum craniectomy diameter

B: maximum anterior-posterior skull diameter

C: extracerebral herniation magnitude

D: horizontal brain diameter

E: brain width ipsilateral to craniectomy

$\mathrm{F}$ : brain width contralateral to craniectomy

D2: horizontal brain diameter

FIG. 2. Diagrams showing CT morphometrics for each group. A demonstration of the measurements taken from the first postoperative CT scan for patients in the DC (top left) and HC (bottom left) groups is shown. The measurements that were obtained are listed on the bottom right, along with corresponding indicators. At the same approximate level on the last preoperative CT scan (right) the maximal preoperative horizontal brain diameter was obtained (D2).

Craniotomy and Temporal Craniectomy. Bur holes were fashioned at the pterion (exposing frontal and temporal dura), the temporal region, the posterior parietal region, and the frontal region, with each bur hole placed as close to the scalp incision as possible. The dura was stripped from each bur hole using a dissector. A large bone flap was fashioned and elevated off the underlying dura. A temporal craniectomy was begun by using a large rongeur, and the temporal bone was resected to the floor of the middle fossa. The temporal craniectomy was completed by using a large $(5-\mathrm{mm})$, rough, diamond drill bit to ensure adequate bone hemostasis. The sphenoid wing could also be drilled to ensure an adequate hinge effect. The bone edges were inspected and any violation of the mastoid air cells or frontal sinus was then appropriately addressed using bone wax or a local pericranial graft.

Dural Opening and Evacuation of Hematoma. In the specific case of SDH the dura was often fenestrated first to allow for evacuation of the SDH while the underlying brain was gradually rather than abruptly decompressed. The dural leaves are connected to form a roughly cruciate pattern. In the case of stroke or intraparenchymal hematoma the dura was opened in a cruciate fashion. Large intraparenchymal hematomas were then evacuated through a corticotomy using suction, irrigation, and ring forceps. Intradural hemostasis was obtained using bipolar cautery and packing and was then confirmed by return of clear irrigation.

Dural Closure and Bone Plate Placement. After intradural hemostasis had been confirmed, the dural leaves were laid over the surface of the brain. Duragen (Integra LifeSciences Corp.) was placed between any dural de- fects. The bone edges were inspected and epidural tackup sutures were placed for epidural hemostasis. If a DC was performed, at this juncture, the bone plate was packaged for storage in the tissue bank for replacement at a later date. If an $\mathrm{HC}$ was performed, 3 miniplates were fastened: a Y-shaped plate just posterior to the coronal suture, and two 2-hole plates, 1 at the sphenoid wing and a second in the posterior temporal region both below the temporalis muscle and fascia. The Y-shaped plate was secured to the surrounding skull while the 2-hole plates acted as buttress plates to prevent future settling (Fig. 1).

Soft Tissue Closure. The temporalis muscle but not the fascia was then reapproximated with sutures, thus allowing for greater cerebral expansion. Care was taken to ensure that the buttress plates were placed underneath the temporalis muscle so that the scalp was protected from the underlying hardware. The galea could then be scored with monopolar cautery, and the galea of the surrounding scalp could be undermined to encourage further scalp expansion. The scalp was then closed in two layers.

\section{Clinical Analysis}

Patient Demographics. Preoperative demographics reviewed for each patient included: patient age, BMI, sex, indication for decompression, laterality of decompression, preoperative pupillary examination, motor GCS score, preoperative use of anticoagulation or antiplatelet agents, coagulation studies (PT, PTT, and INR), and need for correction of coagulopathies.

Postoperative Results. Several postoperative variables were analyzed, including: 1) postoperative ICP control, which was measured by the average daily ICP for each of the first 5 postoperative days and average overall ICP for the duration of monitoring; 2) ICP TII, determined for each day of ICP measurement based on maximal therapy required for ICP control (Table 1); 3) operative time of cerebral decompression procedure; 4) need for reoperation; 5) duration of mechanical ventilation and ICU stay; and 6) hospital survival.

\section{Radiographic Analysis}

For each patient undergoing cranial decompression, both the immediate preoperative and postoperative cranial CT scans were reviewed and classified based on the following characteristics: midline shift, status of basal cisterns (present, compressed, effaced), and the presence of uncal herniation, midbrain torsion (as assessed by deformation of the cerebral peduncle and midbrain tegmentum), IVH, subarachnoid hemorrhage, SDH, and/or EDH. In addition, for each CT scan, a Rotterdam score was calculated (Table 2). ${ }^{13}$

Volumetric Analysis and CT Morphometrics. BrainLAB iPlan software (BrainLAB) was used to calculate the volumetric cerebral volume and ICH volume of both the preoperative and postoperative cranial CT scans for each patient. The volume of cerebral expansion and hematoma volume change was then calculated according to the following formulas: 1) volume of cerebral expansion 
Hinge craniotomy versus decompressive craniectomy

TABLE 4: Summary of patients undergoing DC*

\begin{tabular}{|c|c|c|c|c|c|c|c|}
\hline Category & $\begin{array}{l}\text { Age (yrs), } \\
\text { Sex }\end{array}$ & $\begin{array}{l}\text { Motor GCS } \\
\text { Score }\end{array}$ & Mechanism & CT Finding & $\begin{array}{l}\text { MLS } \\
(\mathrm{mm})\end{array}$ & $\begin{array}{l}\text { Rotterdam } \\
\text { Score }\end{array}$ & Survival \\
\hline \multicolumn{8}{|l|}{ trauma } \\
\hline & $59, \mathrm{M}$ & 1 & fall & $\mathrm{SDH}$ & 15 & 6 & no \\
\hline & $41, \mathrm{~F}$ & 5 & fall & $\mathrm{SDH}$ & 16 & 5 & yes \\
\hline & $10, M$ & 3 & pedestrian vs automobile & SDH, EDH & 6 & 6 & yes \\
\hline & $46, \mathrm{M}$ & 4 & MVA & $\mathrm{SDH}, \mathrm{ICH}$ & 6 & 6 & no \\
\hline & $23, \mathrm{M}$ & 5 & MCC & $\mathrm{SDH}, \mathrm{ICH}$ & 7 & 4 & yes \\
\hline & $22, \mathrm{M}$ & 4 & MVA & $\mathrm{SDH}$ & 9 & 5 & yes \\
\hline & $30, \mathrm{M}$ & 5 & assault & SDH, EDH & 8 & 5 & yes \\
\hline & $36, F$ & 5 & pedestrian vs automobile & $\mathrm{SDH}, \mathrm{ICH}$ & 7 & 3 & yes \\
\hline & $41, \mathrm{~F}$ & 5 & fall & $\mathrm{SDH}, \mathrm{ICH}$ & 10 & 4 & yes \\
\hline & $48, M$ & 2 & fall & $\mathrm{SDH}$ & 18 & 5 & yes \\
\hline & $27, \mathrm{M}$ & 4 & fall & $\mathrm{SDH}, \mathrm{ICH}$ & 8 & 6 & yes \\
\hline & $47, \mathrm{M}$ & 4 & MCC & $\mathrm{SDH}, \mathrm{ICH}$ & 0 & 5 & no \\
\hline & $16, \mathrm{M}$ & 5 & fall & $\mathrm{SDH}$ & 5 & 5 & yes \\
\hline & $75, M$ & 6 & fall & $\mathrm{SDH}$ & 8 & 4 & no \\
\hline & $20, M$ & 2 & assault & $\mathrm{EDH}$ & 11 & 3 & yes \\
\hline & $28, \mathrm{M}$ & 2 & assault & $\mathrm{SDH}$ & 22 & 6 & no \\
\hline & $66, \mathrm{M}$ & 1 & ATV rollover & $\mathrm{SDH}, \mathrm{ICH}$ & 4 & 5 & no \\
\hline & $48, M$ & 4 & fall & SDH & 13 & 4 & yes \\
\hline \multicolumn{8}{|l|}{ infarct } \\
\hline & $65, \mathrm{~F}$ & 6 & rt MCA embolus & hypodensity > 2/3 MCA distribution & 6 & 3 & yes \\
\hline & $42, \mathrm{M}$ & 4 & It ICA dissection & $\begin{array}{l}36 \mathrm{ml} \mathrm{ICH} \text { within previous MCA } \\
\text { infarct }\end{array}$ & 10 & 4 & yes \\
\hline & $63, M$ & 5 & rt M1 occlusion & hypodensity > 2/3 MCA distribution & 11 & 4 & yes \\
\hline & $30, M$ & 4 & rt M1 thrombus & hypodensity > 2/3 MCA distribution & 11 & 4 & yes \\
\hline & $57, M$ & 5 & $\begin{array}{l}\text { rt ICA dissection, rt M1 } \\
\text { thrombus }\end{array}$ & hypodensity > 2/3 MCA distribution & 2 & 2 & no \\
\hline & $79, M$ & 6 & rt M1 embolus & hypodensity > 2/3 MCA distribution & 9 & 3 & yes \\
\hline \multicolumn{8}{|c|}{ 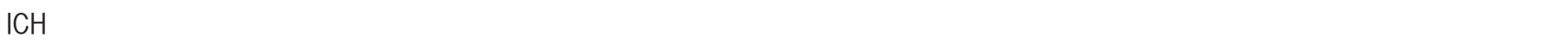 } \\
\hline & $22, \mathrm{M}$ & 6 & postop ICH into tumor bed & $41 \mathrm{ml}$ of $\mathrm{rt}$ frontal ICH & 17 & 5 & yes \\
\hline & $42, \mathrm{~F}$ & 1 & hypertensive hemorrhage & diffuse IVH w/hydrocephalus & 0 & 3 & yes \\
\hline & $57, \mathrm{M}$ & 5 & hypertensive hemorrhage & $96 \mathrm{ml} r t$ thalamic ICH & 17 & 5 & no \\
\hline & $69, \mathrm{M}$ & 6 & anticoagulation-induced & $75 \mathrm{ml} \mathrm{rt} \mathrm{thalamic} \mathrm{ICH}$ & 10 & 5 & no \\
\hline & $58, F$ & 6 & $\begin{array}{l}\text { hemorrhagic conversion rt } \\
\text { MCA infarct }\end{array}$ & $22 \mathrm{ml}$ rt frontal ICH & 10 & 4 & yes \\
\hline & $48, M$ & 5 & hypertensive hemorrhage & $67 \mathrm{ml}$ It basal ganglia ICH w/IVH & 6 & 4 & yes \\
\hline
\end{tabular}

* ATV = all terrain vehicle.

$=$ postoperative volumetric cerebral volume - preoperative volumetric cerebral volume and 2) hematoma volume change $=$ postoperative volumetric $\mathrm{ICH}$ volume - preoperative volumetric ICH volume

Utilizing the technique detailed by Flint et al., ${ }^{5}$ a series of CT scan measurements was used to standardize the size of cranial decompression between patients (Fig. 2).

\section{Statistical Analysis}

Each of the clinical and radiographic characteristics was compared between the HC and DC groups. The independent 2-sample t-test was used for comparison of variables of normal distribution. For nonparametric analysis, the Wilcoxon-Mann-Whitney test was used. Statistical significance was defined as $\mathrm{p}<0.05$. 
TABLE 5: Patient demographics according to group*

\begin{tabular}{lll}
\hline \multicolumn{1}{c}{ Variable } & \multicolumn{1}{c}{ HC } & \multicolumn{1}{c}{ DC } \\
\hline no. of patients & 20 & 30 \\
M:F ratio & $14: 6$ & $24: 6$ \\
mean patient age & $50.5 \pm 15.5$ & $43.8 \pm 18.4$ \\
mean BMI & $26.8 \pm 4.9$ & $25.9 \pm 4.3$ \\
surgical indication & & \\
$\quad$ trauma & $12(60)$ & $18(60)$ \\
$\quad$ infarct & $4(20)$ & $6(20)$ \\
$\quad$ ICH & $4(20)$ & $6(20)$ \\
side of decompression & & \\
$\quad$ rt & $13(65)$ & $23(77)$ \\
$\quad$ It & $7(35)$ & $7(23)$ \\
pupillary examination result & & \\
$\quad$ equal/reactive & $11(55)$ & $13(43)$ \\
$\quad$ anisocoric & $7(35)$ & $14(47)$ \\
$\quad$ fixed/dilated & $2(10)$ & $2(7)$ \\
$\quad$ unable to assess & 0 & $1(3)$ \\
mean motor GCS score & $4.1 \pm 1.4$ & $4.2 \pm 1.6$ \\
no. w/use of anticoagulation/antiplatelet & $6(30)$ & $7(23)$ \\
$\quad$ agents & & \\
mean PT (sec) & $16.5 \pm 19.8$ & $12.2 \pm 3.9$ \\
mean PTT (sec) & $26.9 \pm 8.4$ & $24.9 \pm 3.4$ \\
mean INR & $1.6 \pm 1.9$ & $1.2 \pm 0.5$ \\
required correction for coagulopathy & $3(15)$ & $3(10)$ \\
\hline
\end{tabular}

* All values are number of patients (\%) unless otherwise indicated. None of the variables were statistically significant between groups.

\section{Results}

A total of 50 patients were reviewed, 20 who received an $\mathrm{HC}$ and 30 who received a DC. The indication for cerebral decompression was trauma (12 patients in the $\mathrm{HC}$ group, 18 patients in the DC group), ischemic stroke (4 patients in the $\mathrm{HC}$ group, 6 patients in the DC group), and ICH (4 patients in the HC group, 6 patients in the DC group). Within the category of trauma, the primary indication for surgery was evacuation of a mass lesion in 26 patients $(87 \%)$ and posttraumatic swelling in 4 patients (13\%; Tables 3 and 4).

\section{Demographics}

There were no statistically significant differences (p $<0.05$ ) among any of the preoperative demographic variables: patient age, BMI, sex, surgical indication, side of decompression, pupillary examination result, motor GCS score, use of anticoagulation/antiplatelet agents, coagulation studies, and need for correction of coagulopathy (Table 5).

\section{Postoperative Results}

There was no statistically significant difference $(\mathrm{p}<$ 0.05 ) in either postoperative ICP control or ICP TII be-
T.J. Kenning, R.H. Gandhi, and J.W. German

TABLE 6: Intracranial pressure control summary*

\begin{tabular}{lcc}
\hline ICP Measurement Time Point & $\begin{array}{c}\text { HC Group ICP } \\
(\mathrm{mm} \mathrm{Hg})\end{array}$ & $\begin{array}{c}\text { DC Group ICP } \\
(\mathrm{mm} \mathrm{Hg})\end{array}$ \\
\hline length of monitoring & $12.0 \pm 5.6$ & $12.7 \pm 4.4$ \\
POD 1 & $10.1 \pm 5.9$ & $12.1 \pm 6.7$ \\
POD 2 & $13.4 \pm 8.2$ & $12.4 \pm 5.1$ \\
POD 3 & $11.3 \pm 3.5$ & $13.1 \pm 5.9$ \\
POD 4 & $11.9 \pm 3.2$ & $13.1 \pm 5.5$ \\
POD 5 & $12.1 \pm 2.6$ & $15.0 \pm 6.3$ \\
\hline
\end{tabular}

* All values are means \pm SDs. None of the values were statistically significant between groups. Abbreviation: POD = postoperative day.

tween groups (Tables 6 and 7; Figs. 3 and 4). Both groups demonstrated adequate ICP control as evidenced by the average ICP for the duration of monitoring (12.0 \pm 5.6 $\mathrm{mm} \mathrm{Hg}$ in the $\mathrm{HC}$ group vs $12.7 \pm 4.4 \mathrm{~mm} \mathrm{Hg}$ in the DC group) at a low average TII (1.2 \pm 0.3 in the HC group vs $1.2 \pm 0.4$ in the DC group). All patients received head elevation and sedation as a daily therapeutic measure with only a few requiring more intensive treatment. There was no significant difference between the 2 groups in terms of operative time, need for reoperation, duration of mechanical ventilation, ICU stay, or hospital survival (Table 8).
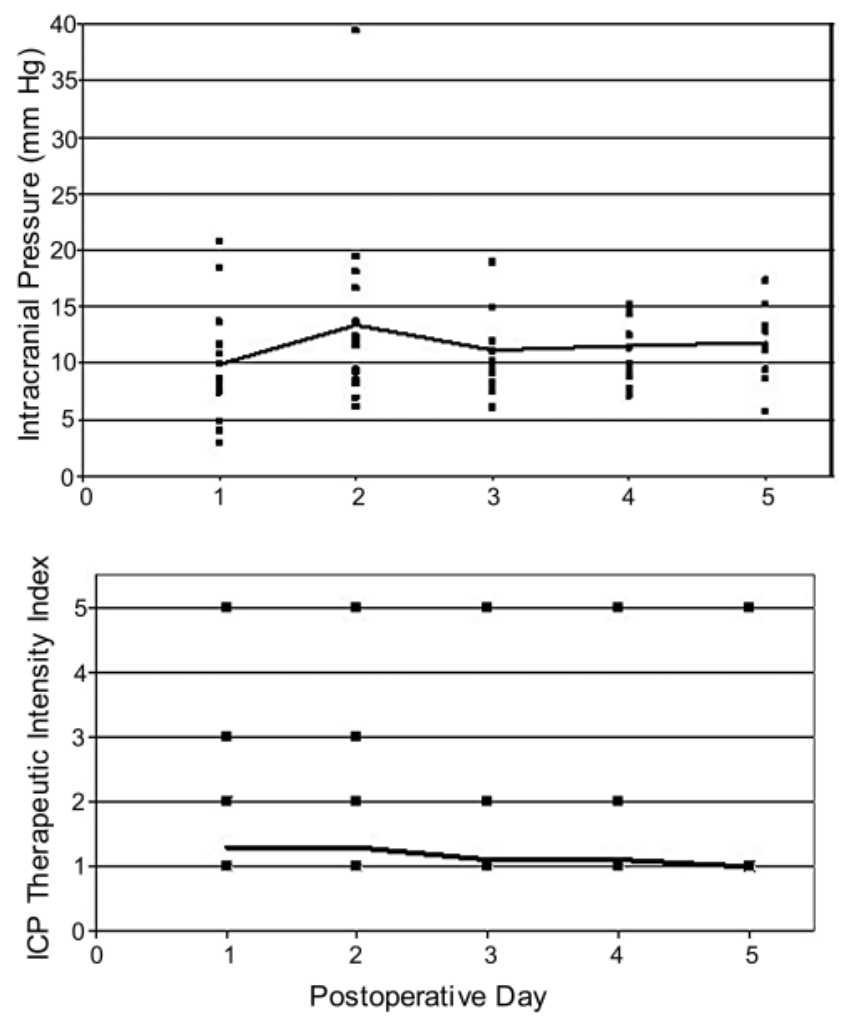

FIG. 3. Line graphs of the average daily ICP recordings (upper) and ICP TII (lower) for each of the patients in the HC group with ICP monitoring during the first 5 postoperative days. The solid line represents the overall average for the groups in each graph. 
Hinge craniotomy versus decompressive craniectomy

TABLE 7: Intracranial pressure TII summary*

\begin{tabular}{lcc}
\hline $\begin{array}{l}\text { TII Measurement } \\
\text { Time Point }\end{array}$ & HC Group TII & DC Group TII \\
\hline average & $1.2 \pm 0.3$ & $1.2 \pm 0.4$ \\
POD 1 & $1.3 \pm 0.5$ & $1.1 \pm 0.3$ \\
POD 2 & $1.3 \pm 0.6$ & $1.1 \pm 0.5$ \\
POD 3 & $1.1 \pm 0.3$ & $1.1 \pm 0.3$ \\
POD 4 & $1.1 \pm 0.3$ & $1.0 \pm 0.2$ \\
POD 5 & $1.0 \pm 0.0$ & $1.3 \pm 0.8$ \\
\hline
\end{tabular}

* All values are means \pm SDs. None of the values were statistically significant between groups.

\section{Radiographic Analysis}

Analyzing the immediate preoperative and postoperative cranial CT scans for both groups revealed no differences that were statistically significant (Table 9). Both groups had comparable baseline radiographic study results and achieved comparable postoperative results. The imaging in 15 of the patients revealed a reversal in the direction of the midline shift between the preoperative and postoperative scans (Fig. 5). A larger proportion of these patients were in the DC group (11 [37\%] of 30) than the HC group (4 [20\%] of 20). This subset of the DC group also experienced a greater overall preoperative to postoperative change in midline shift than the $\mathrm{HC}$ subset $(14.8 \pm 7.7 \mathrm{~mm}$ in the HC group vs $16.0 \pm 6.4 \mathrm{~mm}$ in the DC group) although this difference was not statistically significant.

\section{Volumetric Analysis and CT Morphometrics}

Although a smaller volume of cerebral expansion was associated with the HC group $(77.5 \pm 54.1 \mathrm{ml})$ than the DC group $(105.1 \pm 65.1 \mathrm{ml})$, this difference was also not statistically significant (Table 9). Analysis of morphometric characteristics of the cranial CT scans for both the HC and DC groups revealed similar results (Table 10). The maximum craniectomy diameter was comparable between the two groups even when standardized for different cranial sizes. The extracerebral herniation magnitude varied but not to a statistically significant degree. However, when extracerebral herniation was expressed as a ratio with the maximum craniectomy diameter, creating the extracerebral herniation index, the difference between the $\mathrm{HC}$ and DC groups was statistically significant $(0.16$ \pm 0.05 in the $\mathrm{HC}$ group vs $0.21 \pm 0.06$ in the $\mathrm{DC}$ group; $\mathrm{p}=0.007)$.

\section{Discussion}

The use of HC for cerebral decompression was intro-

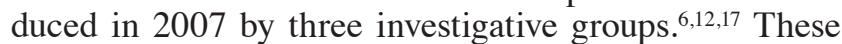
studies were primarily technical reports describing the nuances of the procedure (such as enlarging the subgaleal space, plating of the autologous flap, and performing a galeatomy). Although adequate postoperative ICP control was reportedly obtained, no objective data were pro-
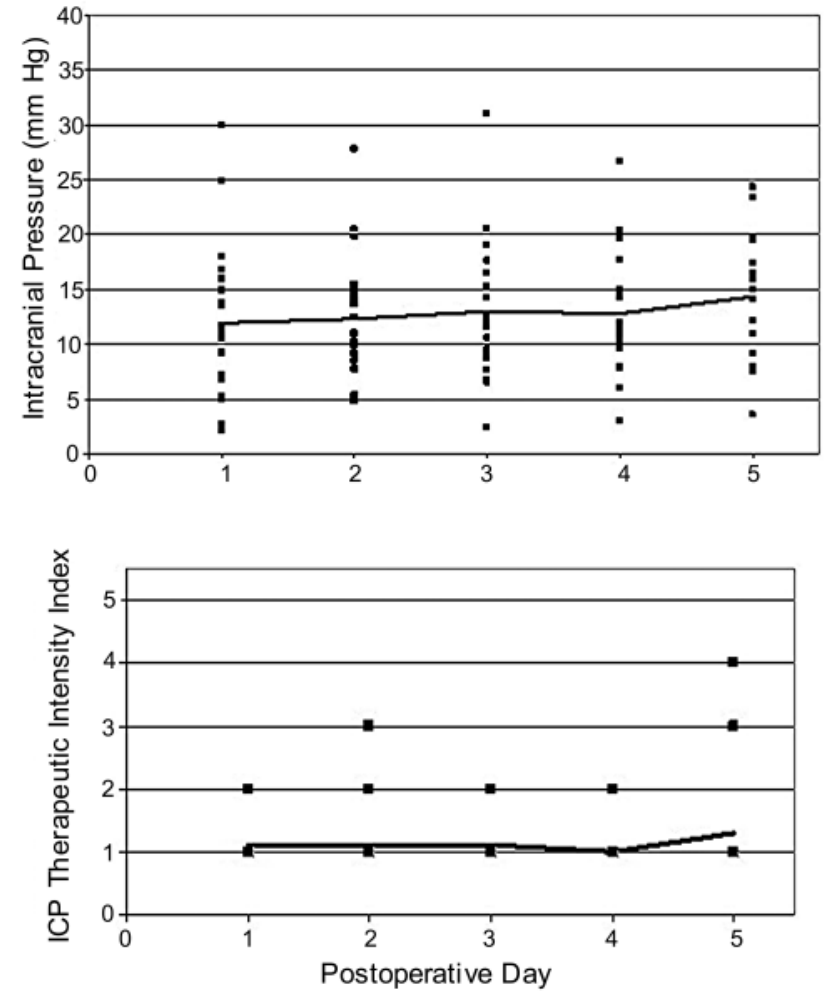

Figure 4. Line graphs of the average daily ICP recordings (upper) and ICP TII (lower) for each of the patients in the DC group with ICP monitoring during the first 5 postoperative days. The solid line represents the overall average for the groups in each graph.

vided to demonstrate this assertion. Overall, the survival of the patients treated appeared satisfactory. Despite the early promising results with this technique, a comparative analysis of $\mathrm{HC}$ and DC has not yet been published.

Our review of the unilateral cranial decompressions at our institution over a 25-month period appears to demonstrate that $\mathrm{HC}$ is likely comparable to DC. Between the two subgroups of patients, the preoperative clinical and radiographic characteristics were very similar. This similarity helped to ensure that the results from the $\mathrm{HC}$ and DC groups could be reliably compared. No significant end points were statistically different, including radiographic and survival analysis.
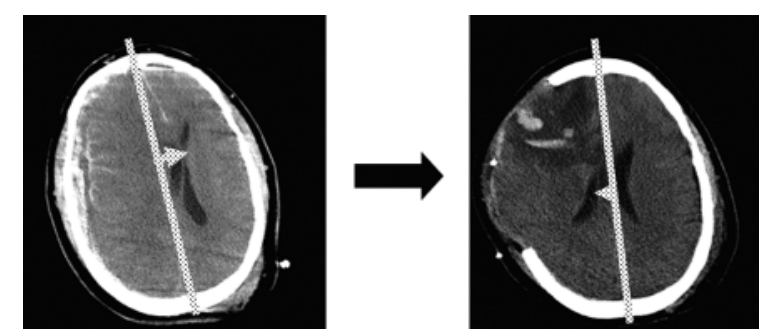

FIG. 5. Computed tomography scans showing postoperative reversal of midline shift. A preoperative CT scan (left) demonstrates a right acute SDH with right-to-left midline shift (arrow). A postoperative CT scan (right) obtained after DC shows extracranial herniation and midline shift from left to right (arrow). 
TABLE 8: Postoperative clinical results*

\begin{tabular}{lll}
\hline \multicolumn{1}{c}{ Variable } & \multicolumn{1}{c}{ HC } & \multicolumn{1}{c}{ DC } \\
\hline mean operative time (min) & $130.4 \pm 71.9$ & $124.9 \pm 63.3$ \\
no. of patients needing reoperations (\%) & $3 / 20(15)$ & $3 / 30(10)$ \\
$\begin{array}{l}\text { mean duration of mechanical ventilation } \\
\quad \text { (days) }\end{array}$ & $9.0 \pm 7.2$ & $11.7 \pm 12.0$ \\
mean ICU stay (days) & $11.6 \pm 7.7$ & $15.6 \pm 15.3$ \\
no. of patients w/ hospital survival (\%) & $15 / 20(75)$ & $21 / 30(70)$ \\
\hline
\end{tabular}

* None of the variables were statistically significant between groups.

\section{Effect of HC on Postoperative ICP}

The most important finding of this study was that the two procedures achieved equivalent ICP control, limiting the need for aggressive medical therapy. This was true despite a smaller volume of cerebral expansion in association with $\mathrm{HC}$. It appears that both $\mathrm{HC}$ and $\mathrm{DC}$ provide adequate space for critical brain swelling.

In addition, we encountered a pair of surprising observations in our review. The first observation was the number of patients who experienced a reversal in the direction of the midline shift between the preoperative and postoperative scans. This shift occurred in a greater number and proportion of patients in the DC group, and these sets of images also showed a greater magnitude in the overall preoperative to postoperative change of midline shift when compared with the HC group.

The second observation was the difference between $\mathrm{HC}(0.16 \pm 0.05)$ and $\mathrm{DC}(0.21 \pm 0.06)$ in the extracerebral herniation index, which was the only statistically significant value in our CT analysis. The extracerebral hernia- tion index compared the magnitude of extracerebral herniation with the maximum diameter of the craniectomy in ratio form. A higher index occurs with a significant degree of extracerebral herniation through the cranial defect. Conversely, a smaller index would indicate less extracerebral herniation in comparison with the defect. Despite a comparable size of cranial decompression between HC and DC (as evidenced by our morphometric analysis) and similar postoperative ICPs at a similar TII, this index was smaller in the HC group.

These two findings of change in the direction of midline shift and the extracerebral herniation index may suggest that DC results in a greater degree of postoperative brain deformation when compared with HC. We speculate that this change may be a result of the rapid cerebral decompression that occurs with DC and the theoretical risk of increased edema with greater cerebral expansion. ${ }^{18}$ These features of DC may place the patient at a greater risk for venous congestion and potential infarction with hemorrhagic conversion along the boundaries of the cranial defect.

In addition, although the difference was not statistically significant, our analysis revealed a greater degree of postoperative parenchymal contusion enlargement with DC. This enlargement may reflect blossoming of the contusions secondary to unconstrained brain expansion, which may portend a worse neurological outcome as previously demonstrated by Flint et al. ${ }^{5}$ By leaving the native bone plate in place during $\mathrm{HC}$, there is a possibility that these effects may be avoided while still achieving the desired ICP control.

\section{Study Limitations}

The limitations of this study include the heterogene-

TABLE 9: Preoperative and postoperative radiographic results according to group*

\begin{tabular}{|c|c|c|c|c|}
\hline \multirow[b]{2}{*}{ Variable } & \multicolumn{2}{|c|}{$\mathrm{HC}$} & \multicolumn{2}{|c|}{ DC } \\
\hline & Preop & Postop & Preop & Postop \\
\hline mean MLS (mm) & $11.0 \pm 4.7$ & $6.4 \pm 4.4$ & $9.4 \pm 5.2$ & $5.5 \pm 4.6$ \\
\hline \multicolumn{5}{|l|}{ cisterns } \\
\hline effaced & $9(45)$ & $1(2)$ & $8(27)$ & $4(13)$ \\
\hline compressed & $8(40)$ & $2(10)$ & $12(40)$ & $4(13)$ \\
\hline present & $3(15)$ & $17(85)$ & $10(33)$ & $22(73)$ \\
\hline uncal herniation & $13(65)$ & $2(10)$ & $18(60)$ & $5(17)$ \\
\hline midbrain torsion & $4(20)$ & $4(20)$ & $2(7)$ & $2(7)$ \\
\hline IVH & $6(30)$ & $7(35)$ & $8(27)$ & $10(33)$ \\
\hline $\mathrm{SAH}$ & $12(60)$ & $9(45)$ & $17(57)$ & $14(47)$ \\
\hline $\mathrm{SDH}$ & $12(60)$ & $14(70)$ & $17(57)$ & $15(50)$ \\
\hline $\mathrm{EDH}$ & $2(10)$ & $1(5)$ & $3(10)$ & $2(7)$ \\
\hline mean Rotterdam score & $4.8 \pm 1.1$ & $3.2 \pm 1.0$ & $4.4 \pm 1.1$ & $3.4 \pm 1.3$ \\
\hline mean VCE (ml) & & $77.5 \pm 54.1$ & & $105.1 \pm 65.1$ \\
\hline mean hematoma volume (ml) & $12.3 \pm 27.3$ & $21.9 \pm 27.7$ & $4.4 \pm 6.0$ & $22.5 \pm 37.5$ \\
\hline mean hematoma volume change (ml) & & $8.9 \pm 17.2$ & & $14.7 \pm 31.9$ \\
\hline
\end{tabular}

* All values are number of patients (\%) unless otherwise indicated. None of the variables were statistically significant between groups. Abbreviation: VCE = volume of cerebral expansion. 


\section{Hinge craniotomy versus decompressive craniectomy}

TABLE 10: Computed tomography morphometric results*

\begin{tabular}{|c|c|c|c|}
\hline CT Morphometric & HC Group & DC Group & $p$ Value \\
\hline \multirow{2}{*}{$\begin{array}{l}\text { max craniectomy or cra- } \\
\text { niotomy diameter (mm) } \\
\text { ratio† }\end{array}$} & $124.8 \pm 20.7$ & $124.0 \pm 10.8$ & NS \\
\hline & $0.79 \pm 0.14$ & $0.80 \pm 0.10$ & NS \\
\hline \multicolumn{4}{|l|}{ ECH magnitude $(\mathrm{mm})$} \\
\hline & $21.2 \pm 9.5$ & $26.0 \pm 7.7$ & NS \\
\hline \multicolumn{4}{|l|}{ ECH index } \\
\hline & $0.16 \pm 0.05$ & $0.21 \pm 0.06$ & 0.007 \\
\hline \multicolumn{4}{|l|}{ \% lateral brain expansion§ } \\
\hline & $107.4 \pm 3.9$ & $107.7 \pm 6.2$ & NS \\
\hline \multicolumn{4}{|c|}{$\begin{array}{l}* \mathrm{ECH}=\text { extracerebral herniation; NS }=\text { not significant. } \\
\dagger \text { ratio }=\text { max craniectomy or craniotomy diameter/max anteroposterior } \\
\text { skull diameter. } \\
\$ \mathrm{ECH} \text { index }=\mathrm{ECH} \text { magnitude/max craniectomy or craniotomy diam- } \\
\text { eter. } \\
\S \% \text { lateral brain expansion }=(\text { postop horizontal brain diameter }-\mathrm{im} \text { - } \\
\text { mediate preop horizontal brain diameter }) \times 100 \text {. }\end{array}$} \\
\hline
\end{tabular}

ity of the patient population, its retrospective nonrandomized nature, limited size, and lack of long-term outcomes. The operative decision-making was not uniform as the type of decompression performed was at the discretion of the treating neurosurgeon. In the majority of patients, no preoperative ICP data are available because the patients were taken directly to the operating room after showing evidence of a clinical herniation syndrome or a mass lesion producing a significant midline shift. The measurement of metabolic parameters (such as microdialysis and cerebral oxygenation) was not used because the patients treated predated the use of these techniques at our institution. Finally, despite its routine use in neurooncology, the technique of assessing cerebral volume with the BrainLAB software has not yet been validated. Future studies will involve validation of this technique as well as longterm analysis of these patients, including neurological outcomes and assessment of adequate osteosynthesis.

This is the first study to evaluate the cerebral decompression techniques of $\mathrm{HC}$ and $\mathrm{DC}$ through a review of postoperative ICP control in the context of a TII. We have demonstrated that, in comparison with DC and in patients with comparable underlying pathology, the early ICP and survival goals are equivalent and acceptable in HC. These findings, in combination with the potential benefits of avoiding both the immediate morbidity of DC (such as seizures, protective headgear, and syndrome of the trephined) and the eventual cranioplasty, make $\mathrm{HC}$ an attractive option for cerebral decompression and one that warrants further study.

\section{Conclusions}

Our results suggest that $\mathrm{HC}$ may be widely applicable for cerebral decompression rather than just in borderline cases as previously suggested. Hinge craniotomy appears to be at least as good as DC in providing postoperative
ICP control and results in equivalent early clinical outcomes. Long-term outcome analysis as well as a randomized, prospective study is still required.

\section{Disclaimer}

The authors report no conflict of interest concerning the materials or methods used in this study or the findings specified in this paper.

\section{References}

1. Aarabi B, Hesdorffer DC, Ahn ES, Aresco C, Scalea TM, Eisenberg HM: Outcome following decompressive craniectomy for malignant swelling due to severe head injury. J Neurosurg 104:469-479, 2006

2. Albanese J, Leone M, Alliez, et al: Decompressive craniectomy for severe traumatic brain injury: evaluation of the effects at 1 year. Crit Care Med 21:2535-2538, 2003

3. Chen CC, Cho DY, Tsai SC: Outcome of and prognostic factors for decompressive hemicraniectomy in malignant middle cerebral artery infarction. J Clin Neurosci 14:317-321, 2007

4. Cushing H: Subtemporal decompressive operations for the intracranial complication associated with bursting fractures of the skull. Ann Surg 47:641-644, 1908

5. Flint AC, Manley GT, Gean AD, Hemphill JC, Rosenthal G: Post-operative expansion of hemorrhagic contusions after unilateral decompressive hemicraniectomy in severe traumatic brain injury. J Neurotrauma 25:503-512, 2008

6. Goettler CE, Tucci KA: Decreasing the morbidity of decompressive craniectomy: the Tucci flap. J Trauma 62:777-778, 2007

7. Grant GA, Jolley M, Ellenbogen RG, Roberts TS, Gruss JR, Loeser JD: Failure of autologous bone-assisted cranioplasty following decompressive craniectomy in children and adolescents. J Neurosurg 100 (2 Suppl Pediatrics):163-168, 2004

8. Guerra WK, Gaab MR, Dietz H, Mueller JU, Piek J, Fritsch MJ: Surgical decompression for traumatic brain swelling: indications and results. J Neurosurg 90:187-196, 1999

9. Jiang JY, Xu W, Li WP, Xu WH, Zhang J, Bao YH, et al: Efficacy of standard trauma craniectomy for refractory intracranial hypertension with severe traumatic brain injury: a multicenter prospective, randomized controlled study. J Neurotrauma 22:623-628, 2005

10. Kan P, Amini A, Hansen K, et al: Outcomes after decompressive craniectomy for severe traumatic brain injury in children. J Neurosurg 105:337-342, 2006

11. Kilincer C, Simsek O, Hamamcioglu MK, Hicdonmez T, Cobanoglu S: Contralateral subdural effusion after aneurysm surgery and decompressive craniectomy: case report and review of the literature. Clin Neurol Neurosurg 107:412-416, 2005

12. Ko K, Segan S: In situ hinge craniectomy. Neurosurgery 60 (4 Suppl 2):ONS255-ONS259, 2007

13. Maas AI, Steverberg EW, Butcher I, Dammers R, Lu J, Marmarou A, et al: Prognostic value of computerized tomography scan characteristics in traumatic brain injury: results from the IMPACT study. J Neurotrauma 24:303-314, 2007

14. Pillai A, Menon SK, Kumar S, Rajeev K, Kumar A, Panikar D: Decompressive hemicraniectomy in malignant middle cerebral artery infarction: an analysis of long-term outcome and factors in patient selection. J Neurosurg 106:59-65, 2007

15. Ruf B, Heckmann M, Schroth I, Hügens-Penzel M, Reiss I, Borkhardt A, et al: Early decompressive craniectomy and duraplasty for refractory intracranial hypertension in children: results of a pilot study. Crit Care 7:R133-R138, 2003

16. Schirmer CM, Ackil AA, Malek AM: Decompressive craniectomy. Neurocrit Care 8:456-470, 2008

17. Schmidt JH III, Reyes BJ, Fischer R, Flaherty SK: Use of 
T.J. Kenning, R.H. Gandhi, and J.W. German

hinge craniotomy for cerebral decompression: technical note. J Neurosurg 107:678-682, 2007

18. Simard JM, Kent TA, Chen M, Tarasov KV, Gerzanich V: Brain oedema in focal ischaemia: molecular pathophysiology and theoretical implications. Lancet Neurol 6:258-268, 2007

19. Stiver SI, Wintermark M, Manley GT: Reversible monoparesis following decompressive hemicraniectomy for traumatic brain injury. J Neurosurg 109:245-254, 2008

20. Yoo DS, Kim DS, Cho KS, Huh PW, Park CK, Kang JK: Ven- tricular pressure monitoring during bilateral decompression with dural expansion. J Neurosurg 91:953-959, 1999

Manuscript submitted February 15, 2009.

Accepted April 1, 2009.

Address correspondence to: Tyler J. Kenning, M.D., 47 New Scotland Avenue, MC-10, Division of Neurosurgery, Albany Medical Center, Albany, New York 12208. email: kennint@mail.amc.edu. 